
UNDER CONTRACT DE-AC02-76CH03073

PPPL-3591

PPPL-3591

UC-70

\title{
Kinetic Profiles in NSTX Plasmas
}

\section{by}

R.E. Bell, B.P. LeBlanc, C. Bourdelle, D.R. Ernst, E.D. Fredrickson, D.A. Gates, J.C. Hosea, D.W. Johnson, S.M. Kaye, R. Maingi, S. Medley, J.E. Menard, D. Mueller, M. Ono, F. Paoletti, M. Peng, S.A. Sabbagh, D. Stutman, D.W. Swain, E.J. Synakowski, and J.R. Wilson

July 2001

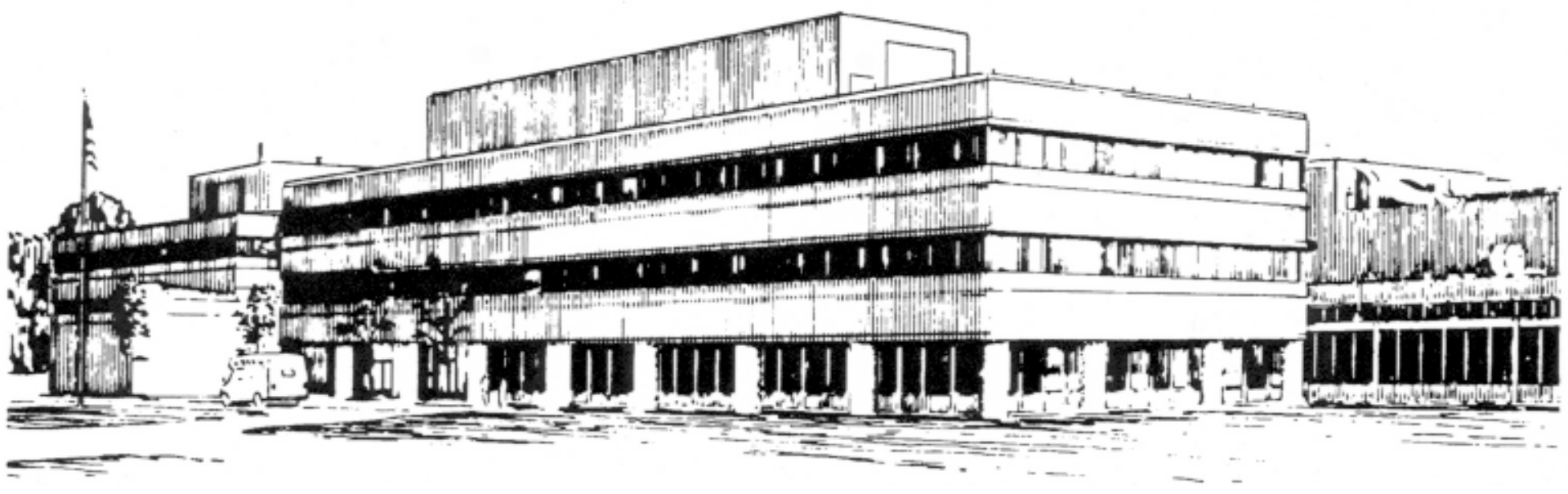




\section{PPPL Reports Disclaimer}

This report was prepared as an account of work sponsored by an agency of the United States Government. Neither the United States Government nor any agency thereof, nor any of their employees, makes any warranty, express or implied, or assumes any legal liability or responsibility for the accuracy, completeness, or usefulness of any information, apparatus, product, or process disclosed, or represents that its use would not infringe privately owned rights. Reference herein to any specific commercial product, process, or service by trade name, trademark, manufacturer, or otherwise, does not necessarily constitute or imply its endorsement, recommendation, or favoring by the United States Government or any agency thereof. The views and opinions of authors expressed herein do not necessarily state or reflect those of the United States Government or any agency thereof.

\section{Availability}

This report is posted on the U.S. Department of Energy's Princeton Plasma Physics Laboratory Publications and Reports web site in Calendar Year 2001. The home page for PPPL Reports and Publications is: http://www.pppl.gov/pub_report/

DOE and DOE Contractors can obtain copies of this report from:

U.S. Department of Energy

Office of Scientific and Technical Information

DOE Technical Information Services (DTIS)

P.O. Box 62

Oak Ridge, TN 37831

Telephone: (865) 576-8401

Fax: (865) 576-5728

Email: reports@adonis.osti.gov

This report is available to the general public from:

National Technical Information Service

U.S. Department of Commerce

5285 Port Royal Road

Springfield, VA 22161

Telephone: 1-800-553-6847 or

(703) 605-6000

Fax: (703) 321-8547

Internet: http://www.ntis.gov/ordering.htm 


\section{KINETIC PROFILES IN NSTX PLASMAS}

R. E. Bell, B. P. LeBlanc, C. Bourdelle, D. R. Ernst, E. D. Fredrickson, D. A. Gates, J. C. Hosea, D. W. Johnson, S. M. Kaye, R. Maingi, ${ }^{a}$ S. Medley, J. E. Menard, D. Mueller, M. Ono, F. Paoletti, ${ }^{b}$ M. Peng, ${ }^{a}$ S. A. Sabbagh, ${ }^{b}$ D. Stutman, ${ }^{c}$ D. W. Swain ${ }^{a}$, E. J. Synakowski, J. R. Wilson

\section{Princeton Plasma Physics Laboratory, P. O. Box 451, Princeton, NJ 08543 USA \\ ${ }^{a}$ Oak Ridge National Laboratory, Oak Ridge, TN 37831 USA \\ ${ }^{b}$ Columbia University, New York, NY USA \\ ${ }^{c} J o h n s$ Hopkins University, Baltimore, MD USA}

\section{Introduction}

The National Spherical Torus Experiment (NSTX) is a low aspect ratio $(R / a \sim 1.3)$ device with auxiliary heating from neutral beam injection (NBI) and high harmonic fast wave heating (HHFW). Typical NSTX parameters are $R_{0}=85 \mathrm{~cm}, a=67 \mathrm{~cm}, I_{p}=0.7-1.4 \mathrm{MA}$, $B_{\phi}=0.25-0.45 \mathrm{~T}$. Three co-directed deuterium neutral beam sources have injected $P_{N B} \leq 4.7 \mathrm{MW}$. HHFW plasmas typically have delivered $P_{R F} \leq 3 \mathrm{MW}$. Important to the understanding of NSTX confinement are the new kinetic profile diagnostics: a multi-pulse Thomson scattering system (MPTS) and a charge exchange recombination spectroscopy (CHERS) system. The MPTS diagnostic currently measures electron density and temperature profiles at $30 \mathrm{~Hz}$ at ten spatial locations. The CHERS system has recently become available to measure carbon ion temperature, $T_{i}$, and toroidal flow, $V_{\phi}$, at 17 radial positions spanning the outer half of the minor radius with $20 \mathrm{~ms}$ time resolution during NBI. Experiments conducted during the last year have produced a wide range of kinetic profiles in NSTX. Some interesting examples are presented below.

\section{Peaked electron density and MHD in ohmic discharges}

A broad range of electron density profiles has been observed to date. Peak central electron densities up to $n_{e}(0)=8 \times 10^{19} \mathrm{~m}^{-3}$ have been measured in ohmic plasmas exhibiting little magnetohydrodynamic (MHD) activity. The appearance of MHD can have a pronounced effect on the electron density profile, in particular. By careful programming of the discharge, an MHD-quiescent plasma will result in a high centrally peaked $n_{e}$ profile. Figure 1 shows the evolution of $n_{e}$ and $T_{e}$ profiles in a discharge that is initially MHD quiescent. The central electron density increases until the onset of an $n=1$ mode which appears at 0.27 seconds as the minimum $q$, as calculated by EFIT[1,2], drops below 1 . In the presence of such MHD activity, 
the central peaking is usually lost and a much broader $n_{e}$ profile results, as seen for the last profile at 0.297 seconds in Fig. 1; the $T_{e}$ profile (Fig. 2b) remains unchanged.

\section{High Harmonic Fast Wave during $I_{p}$ ramp}

High harmonic fast wave yields effective electron heating[3,4]. HHFW power has also been applied during the ramp up of the plasma current, $I_{p}$, to slow current diffusion. This early application of HHFW power into a deuterium plasma resulted in a large density increase, leading to record central electron densities[2]. The initial $n_{e}$ profile was hollow and filled in after about 0.15 seconds (see Fig. 2), producing a broad profile with $n_{e}(0)=8 \times 10^{19} \mathrm{~m}^{-3}$ and steep edge

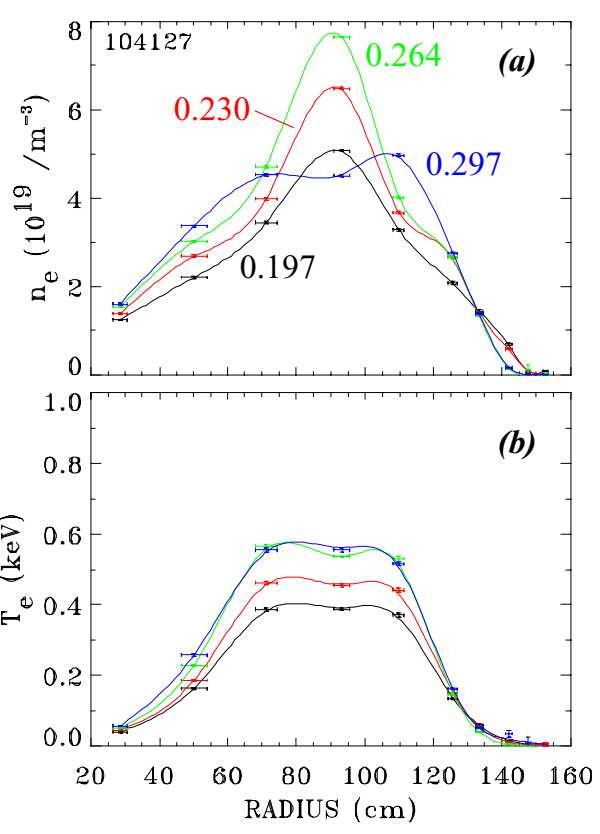

Figure 1. $n_{e}$ and $T_{e}$ profiles during ohmic discharge. Strong central peaking of electron density is lost after onset of $n=1$ mode at 0.27 seconds. density gradients. The density rise occurred without gas.

\section{Ion temperature and velocity during neutral beam injection}

The addition of neutral beam injection in NSTX has allowed the measurement of carbon impurity temperature using charge exchange recombination spectroscopy. The neutral beam sources can be used to heat the plasma or, using a brief pulse of NBI, act as probes of $T_{i}$ and $V_{\phi}$ during ohmic or HHFW experiments. At present, analysis of CHERS data is limited to times when there is a step in the NB power. The application of short neutral beam pulses into ohmic plasmas shows profiles with $T_{i} \sim T_{e}$. During HHFW heating experiments, $T_{e}(0)>T_{i}(0)$ is measured under conditions of strong electron heating.

The initial analysis of CHERS profiles during NB heating shows $T_{i}$ profiles that are typically hotter and broader than $T_{e}$ profiles. Ion temperatures

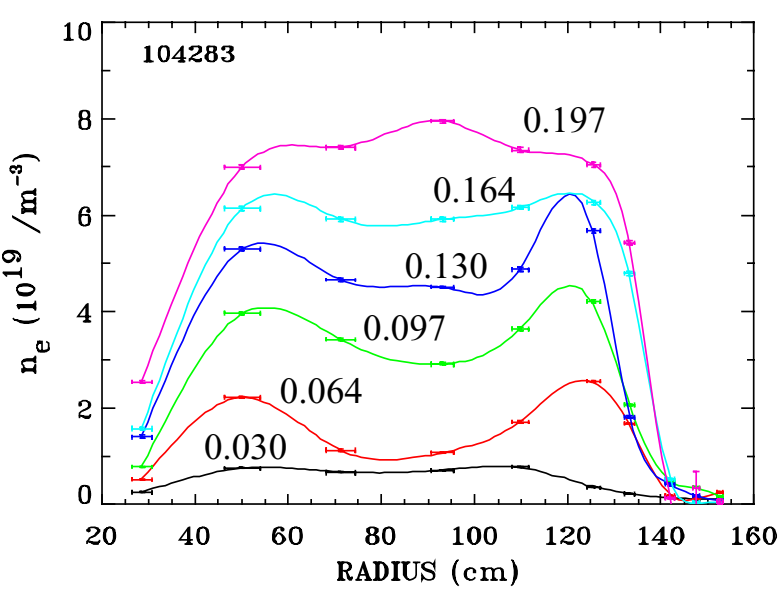

Figure 2. Evolution of the $n_{e}$ profile with the application of HHFW during $I_{p}$ ramp. Time of successive profiles are indicated. 
up to $2 \mathrm{keV}$ have been measured. Shown in Figure 3 are the $T_{i}$ and $V_{\phi}$ profiles for a plasma with a step in the NB power as $I_{p}$ is being ramped up to 1.2 MA. The toroidal impurity velocity during this discharge is the highest measured to date, $V_{\phi} \leq 240 \mathrm{~km} / \mathrm{s}$. This carbon velocity is a significant fraction of the deuterium thermal and Alfvén velocities, $V_{\phi}=0.26 V_{A}^{\text {deuterium }}$ and $V_{\phi}=0.6 V_{\text {th }}^{\text {deuterium }}$.

Figure 4 shows kinetic profiles measured during a high $\beta$ discharge $\left(\beta_{T} \sim 20 \%\right.$ from EFIT based on magnetics only) when a large $\mathrm{m} / \mathrm{n}=1 / 1$ mode was present, just before the $\beta$
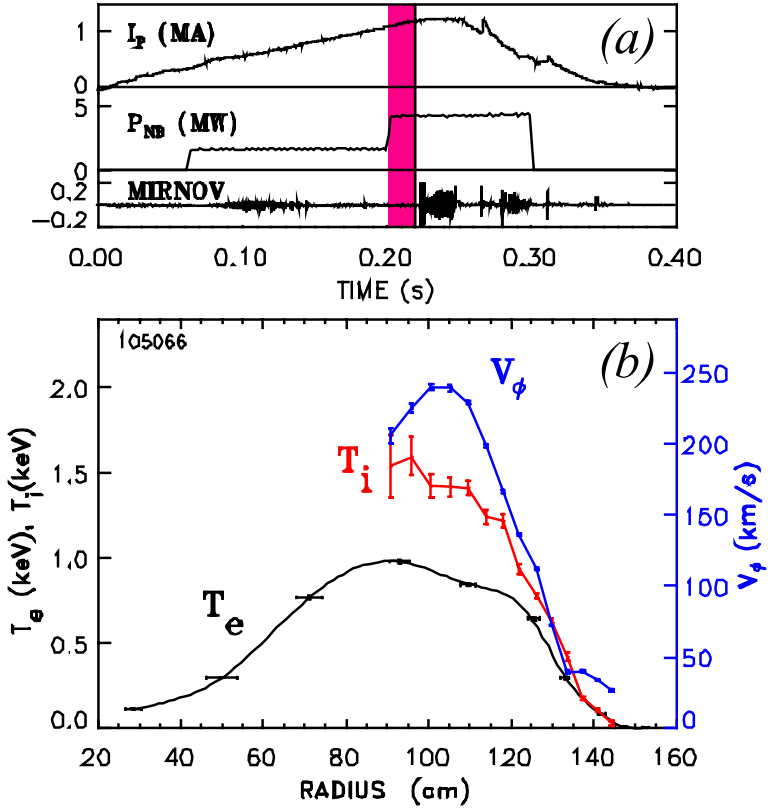

Figure 3. (a) Time of CHERS measurement (shaded) at step in NB power. (b) Profiles showing $T_{I}>T_{e}$ and high $V_{\phi}$. collapse. In Fig. 4a, $T_{i}$ is flat in the center and broader than $T_{e}$ ( $T_{i}$ was measured at 0.215 seconds, compared to $T_{e}$ at 0.197 seconds). The toroidal velocity within a few centimeters of the low field edge is also remarkably high, $V_{\phi}=50 \mathrm{~km} / \mathrm{s}$. In Fig. $4 \mathrm{c}, V_{\phi}$ peaks off axis. In similar discharges, prior to the strong 1/1 mode, the central values of $T_{i}$ and $V_{\phi}$ are more peaked, such as seen in Fig. 3. In Fig. 4d, the flow measurements are plotted in terms of the rotational frequency, $f_{\phi}=V_{\phi} / 2 \pi R$ where $R$ is the
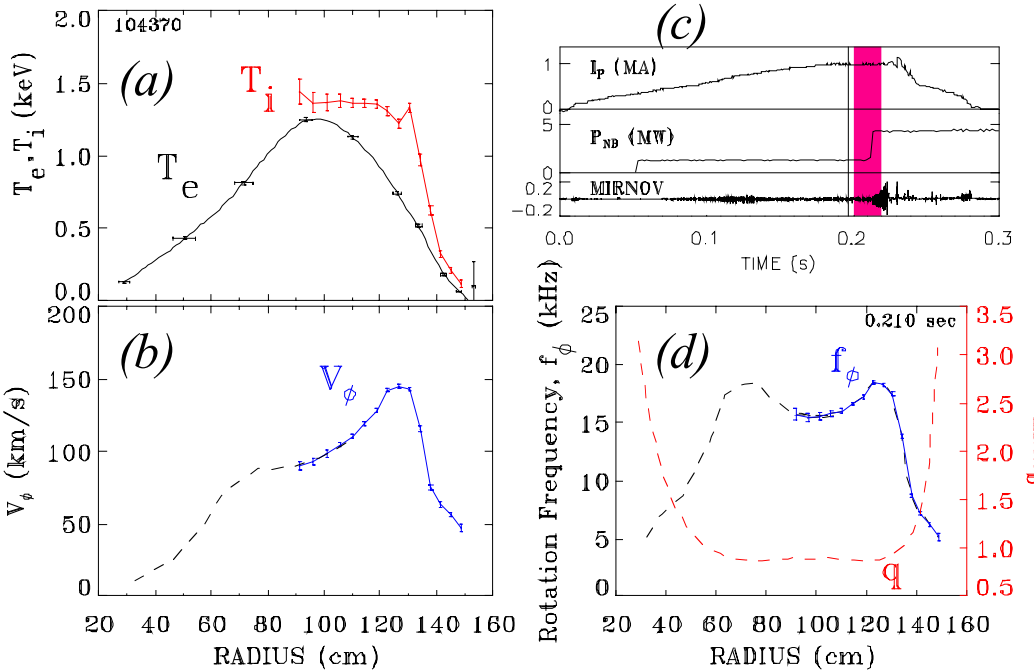

Figure 4. (a) Temperature profiles (b) Toroidal velocity proifle (blue) with inferred values (dashed) assuming $f_{\phi}$ constant on flux surface. (c) Time of CHERS measurements (shaded) at step in $P_{N B}$. (d) Rotational frequency profile with q profile from EFIT. major radius. A hollow $f_{\phi}$ profile results. Isobars from the electron pressure profile were used to map the low field side to the high field. This mapping of $f_{\phi}$ is shown as a dashed line in Fig. 4d, which retraces the measured values that extend inside the magnetic axis. The dashed line in Fig. $4 c$ are the analog linear velocities on the high field side of the magnetic axis which are not 
directly measured. Under the above assumptions, the high measured edge velocity at the outer radii are mapped to velocities which are an order of magnitude lower near the central column of NSTX.

Quite recently, a neutral particle analyzer (NPA)

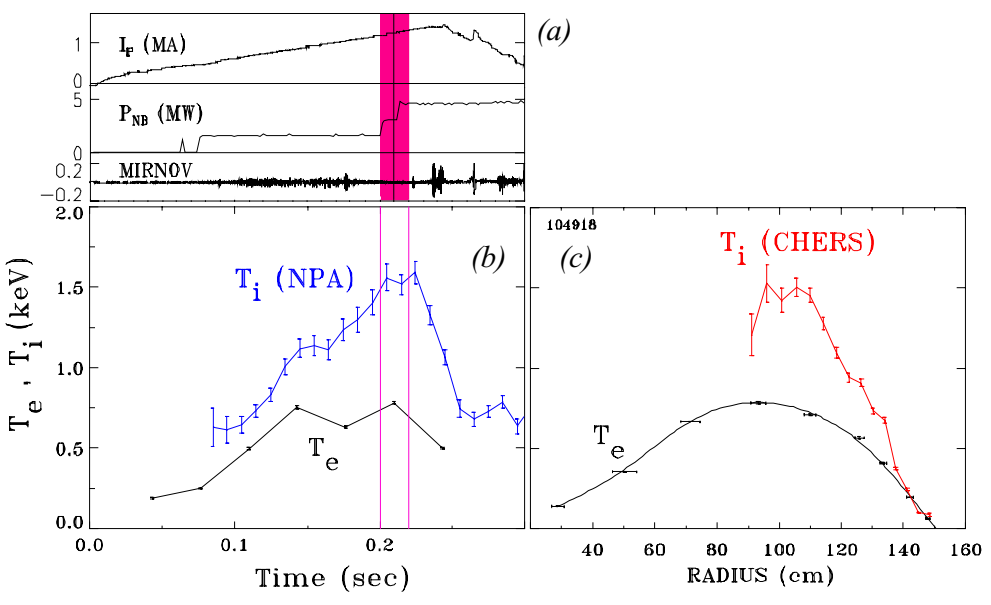
became operational, yielding the first time histories of $T_{i}(0)$

Figure 5. Comparison of temperature measurements from NPA, CHERS, and MPTS. on NSTX. Measurements taken during a 1.4 MA discharge are shown in Fig. 5b along with $T_{e}(0)$ from MPTS. Good agreement is found between the $T_{i}(0)$ from the CHERS profile (Fig. 5c) and $T_{i}$ from NPA taken at the same time.

The measured temperature and velocity profiles during NBI present several puzzles. The difference between $T_{i}$ and $T_{e}$ at some radii is sufficiently large to challenge our understanding of the power balance in terms of classical collisional processes. Electron ion coupling is expected to be strong. Most of the neutral beam power is expected to be delivered to the electrons. However, a power balance calculation indicates that the power flow from ions to electrons exceeds the power delivered to the ions by NBI. Efficient coupling of beam ion energy to thermal ions by stochastic heating from MHD may account for some of the calculated deficit [5]. This could imply a small, but positive, ion thermal conduction and large electron thermal conduction, consistent with recent microstability analyses of these discharges.

\section{Acknowledgements}

This work was supported by the United States Department of Energy under contract number DE-AC02-76CH03073.

1 Lao, L. L. , et al., Nucl. Fusion 25, 1611 (1985).

2 Sabbagh, S. A., et al., Nucl. Fusion (2001), accepted for publication.

3 Wilson, J. R., et al, Proc. $18^{\text {th }}$ IAEA Fusion Energy Conf. (Sorento 2000) EXP 4/08

4 LeBlanc, B. P., et al, Proc. $14^{\text {th }}$ Conf. RF Power in Plasmas (Oxnard 2001) Invited

5 Gates, D. A., Gorlenkov, N., White, R. B., submitted to Phys. Rev. Lett. (2001). 


\section{External Distribution}

Plasma Research Laboratory, Australian National University, Australia

Professor I.R. J ones, Flinders University, Australia

Professor J oão Canalle, Instituto de Fisica DEQ/IF - UERJ , Brazil

Mr. Gerson O. Ludwig, Instituto Nacional de Pesquisas, Brazil

Dr. P.H. Sakanaka, Instituto Fisica, Brazil

The Librarian, Culham Laboratory, England

Library, R61, Rutherford Appleton Laboratory, England

Mrs. S.A. Hutchinson, JET Library, England

Professor M.N. Bussac, Ecole Polytechnique, France

Librarian, Max-Planck-Institut für Plasmaphysik, Germany

J olan Moldvai, Reports Library, MTA KFKI-ATKI, Hungary

Dr. P. Kaw, Institute for Plasma Research, India

Ms. P.J . Pathak, Librarian, Insitute for Plasma Research, India

Ms. Clelia De Palo, Associazione EURATOM-ENEA, I taly

Dr. G. Grosso, Instituto di Fisica del Plasma, Italy

Librarian, Naka Fusion Research Establishment, J AERI, J apan

Library, Plasma Physics Laboratory, Kyoto University, J apan

Research Information Center, National Institute for Fusion Science, J apan

Dr. O. Mitarai, Kyushu Tokai University, J apan

Library, Academia Sinica, Institute of Plasma Physics, People's Republic of China

Shih-Tung Tsai, Institute of Physics, Chinese Academy of Sciences, People's Republic of China

Dr. S. Mirnov, TRINITI, Troitsk, Russian Federation, Russia

Dr. V.S. Strelkov, Kurchatov Institute, Russian Federation, Russia

Professor Peter Lukac, Katedra Fyziky Plazmy MFF UK, Mlynska dolina F-2, Komenskeho Univerzita, SK-842 15 Bratislava, Slovakia

Dr. G.S. Lee, Korea Basic Science Institute, South Korea

Mr. Dennis Bruggink, Fusion Library, University of Wisconsin, USA

Institute for Plasma Research, University of Maryland, USA

Librarian, Fusion Energy Division, Oak Ridge National Laboratory, USA

Librarian, Institute of Fusion Studies, University of Texas, USA

Librarian, Magnetic Fusion Program, Lawrence Livermore National Laboratory, USA

Library, General Atomics, USA

Plasma Physics Group, Fusion Energy Research Program, University of California at San Diego, USA

Plasma Physics Library, Columbia University, USA

Alkesh Punjabi, Center for Fusion Research and Training, Hampton University, USA

Dr. W.M. Stacey, Fusion Research Center, Georgia Institute of Technology, USA

Dr. J ohn Willis, U.S. Department of Energy, Office of Fusion Energy Sciences, USA

Mr. Paul H. Wright, Indianapolis, Indiana, USA 
The Princeton Plasma Physics Laboratory is operated by Princeton University under contract with the U.S. Department of Energy.

\author{
Information Services \\ Princeton Plasma Physics Laboratory \\ P.O. Box 451 \\ Princeton, NJ 08543
}

Phone: 609-243-2750

Fax: 609-243-2751

e-mail: pppl_info@pppl.gov

Internet Address: http://www.pppl.gov 